\title{
EFFECTS OF ABRASIVES DURING ACCELERATED SIMULATION OF MECHANICAL CORROSION OF CEMENT COMPOSITES USING ABRASIVE WATER FLOW
}

\author{
Petr HlaváČéK ${ }^{a, b, *}$, Libor SiteK ${ }^{a, b}$, Dagmar Klichová ${ }^{a}$, \\ LENKA BODNÁROVÁc \\ ${ }^{a}$ Institute of Geonics of the CAS, Studentska 1768, 70800 Ostrava-Poruba, Czech Republic \\ ${ }^{b}$ Institute of Clean Technologies for Mining and Utilization of Raw Materials for Energy Use, 17. listopadu \\ 2172/15, 70833 Ostrava-Poruba, Czech Republic \\ ${ }^{c}$ Brno University of Technology, Faculty of Civil Engineering, Antonínská 548/1, 60190 Brno, Czech Republic \\ * corresponding author: petr.hlavacek@ugn.cas.cz
}

\begin{abstract}
The paper deals with the use of the abrasive water flow technology in an accelerated simulation of the process of mechanical degradation of surface layers of cement-based composites by flowing liquids. Effects of the abrasive particle size and the mass flow rate of abrasives in an abrasive water flow impacting on the surface of concrete samples have been studied. In addition, suitability of the application of the abrasive water flow for the simulation of real situation of the surface wear by flowing liquids has been evaluated.
\end{abstract}

KEYworDs: Cement-based composite, erosion, abrasion, cavitation, high-speed water flow, abrasive material.

\section{INTRODUCTION}

Gradual erosion of concrete surface layers exposed to the effects of flowing liquids is predominantly caused by abrasion and cavitation or, where appropriate, by chemical action. Abrasive erosion of concrete in hydraulic structures is caused by water-transported silt, sand, gravel, ice, or debris while cavitation erosion is a result of the collapse of vapour bubbles formed by pressure changes within a high-speed water flow. The degradation of concrete can be further intensified by chemical attacks or possible action of bacteria [1] Generally, the physical (abrasion and cavitation) and chemical damage complement each other. By the physical damage (such as abrasion), concrete surfaces are often exposed to agents such as acid rain, and therefore the attack by chemical compounds is encouraged. In case of the chemical damage (such as leaching), the concrete becomes more porous, facilitating the process of abrasion, and so on. These facts make both processes of deterioration, physical or chemical, a cycle difficult to dissociate or stabilize [2. Resistance of a particular concrete structure against these types of degradation is influenced by many factors. The most significant are the environmental conditions, dosing of aggregates, concrete strength, the mix ratio, the use of special cement and the use of supplementary materials, such as the addition of fibres and fly ash. Two additional factors have an important effect on the abrasion resistance, i.e. the surface finish and curing conditions [3]. Due to numerous factors, computational modelling of the concrete composition and resistance of the concrete to flowing fluids is a relatively difficult task. Thus, experimental investigation of real structures or test specimens is the only reliable method.

The development of new concrete mixtures, or the determination of suitable surface treatments of concrete long-term-resistant to fast flowing fluids, is often complicated by long and slow degradation of real concrete structures (spillways, stilling basins, walls of the upstream reservoir, drain pipes and hydraulic tunnels, etc.). Measurable degradation occurs within a few months, often after several years or decades. While it is undoubtedly good that the deterioration of real constructions is slow, generally the long-term degradation process unreasonably prolongs any laboratory tests examining the resistance of concretes against the degradation effects of flowing liquids.

There are numerous laboratory methods and recommendations focused on processes of the concrete degradation by the influence of liquids (e.g. [1, [4, [5]). However, due to the nature of the deterioration process and the effort to maintain conditions that are the most similar to the real situation, the testing methods are often time-consuming 6. An extreme case of the long-term laboratory testing of the hydro-abrasive erosion is reported by Binici et al. [7]. The total testing lasted for 3 years. The loss of concrete was investigated once a year. The apparently impractical and inflexible character of these methods encourages the development of new accelerated testing methods.

Certain similarities to the flowing process of frequently contaminated liquids with higher or lower content of free solid particles of various sizes which may already be part of the flowing liquid or were gradually eroded from the original surface of the con- 
crete and consequently carried by the liquid can be seen in the technology of high-speed water flows, i.e. flows moving after the exit from a high-pressure nozzle at speeds of hundreds of $\mathrm{m} \cdot \mathrm{s}^{-1}$. Material is eroded quickly and this method can be applied to faithfully simulate the real erosion processes, if the flow parameters and the testing setup are suitably combined. The mentioned method is relatively commonly used during accelerated testing. Momber and Kovacevic [8] investigated the wear particles occurring during the erosion of concrete after applying the high-velocity water flow. $\mathrm{Hu}$ et al. 9] focused on the hydro-abrasive erosion tests on plain concrete and on steel-fibre reinforced concrete. They particularly studied the method of disintegration of concrete layers at various speeds and angles of impact of the hydro-abrasive suspension. Erosion resistance of several types of concrete and reinforced concretes with a low volume of steel-fibres is compared in another study written by the same authors 10. Experimental work by Momber et al. [11] focuses on the use of acoustic emission sensing technique for the on-line monitoring of hydro-abrasive erosion of five types of pre-cracked concretes. Due to the capability to quantify the amount of the material removed, the method can be recommended for material removal process monitoring. In another work [12], Momber examined the short-time cavitation wear of concrete using the cavitation chamber. The quantification of effects of the kinetic energy and exposure time of the abrasive water flow on the erosion of concretes is described in [13. Behaviour of concretes eroded by water-driven particles and modelling of the process are the subjects of other works [14] and [15].

Many years of experience with the disintegration of cement composites using the high-speed water flows encouraged our team to use this technology for an accelerated mechanical simulation of the degradation process of concrete surfaces affected by flowing fluids. Finding the appropriate configuration and setup of high-speed water flow parameters to faithfully simulate the real erosive process is quite demanding and it requires a large experimental program and a great amount of experience with the water jet technology. In particular, the paper focuses on the effects of the abrasive particle size and the mass flow rate of abrasives during the hydro-dynamic disintegration of concrete using the abrasive water flow.

\section{ABRASivES IN THE WATER FLOW}

Abrasives added to the water flow are commonly used to cut materials. The speed of the abrasive material after the exit from the focusing tube is closely related to the speed of the primary water flow. While the abrasive is accelerated by the water flow, the speed of the water flow decreases. Speed of the suspension of water and abrasives $v_{s}$ at the moment of impact on the cutting material can be expressed for a particular arrangement of the mixing-and-acceleration device. One of the relations determining this dependence was

\begin{tabular}{lr}
\hline Crushing load $\left[\mathrm{kN} \cdot \mathrm{m}^{-1}\right]$ & 57.9 \\
Concrete water absorption [\%] & 3.9 \\
Concrete compressive strength [MPa] & 64.5 \\
Concrete density $\left[\mathrm{kg} \cdot \mathrm{m}^{-3}\right]$ & 2300 \\
\hline
\end{tabular}

TABle 1. Properties of concrete shaft unit.

published, for example, by $\mathrm{Hu}$ et al. [9]:

$$
v_{s}=\chi_{T} \frac{v_{w}}{1+R}
$$

where $\chi_{T}$ is a momentum transfer parameter and $R$ is the ratio between water mass flow rate and particle mass flow rate:

$$
R=\frac{\dot{m}_{p}}{\dot{m}_{w}}
$$

The speed of the water flow $v_{w}$ after the exit from the water nozzle can be expressed using the Bernoulli's law as

$$
v_{w}=\varphi \sqrt{\frac{2 p}{\rho}},
$$

where $\varphi$ is the discharge coefficient, $p$ is the water pressure upstream the nozzle exit and $\rho$ is water density. Similar relations can be found in [16].

However, at usual speeds of the abrasive material (about $600 \mathrm{~m} \cdot \mathrm{s}^{-1}$ at the water pressure of $415 \mathrm{MPa}$, abrasive flow rate of $300 \mathrm{~g} \cdot \mathrm{min}^{-1}$ and abrasive grain size of $180-250 \mu \mathrm{m}$ in the arrangement of standard abrasive mixing head [17]), the abrasive cuts off all structural elements of the concrete, which is far from the erosive wear by abrasion caused by flowing liquids (for instance [13]). One way to "slow down" the process in order to achieve lower speeds of abrasives is to use lower water pressures which generate the water flow (e.g. the speed of abrasive grain is only about $118 \mathrm{~m} \cdot \mathrm{s}^{-1}$ at the water pressure of $80 \mathrm{MPa}$ [18]). Another ways to reduce the cutting capacity of abrasives in the water flow to erode the surface rather than to cut it off are (i) to decrease the abrasive mass flow rate in the flow or (ii) to use finer abrasive. All methods were incorporated into the experimental program. Simultaneously, erosion tests with the water flow without the presence of abrasive were realized for the purpose of comparing the test results.

\section{EXPERIMENTAL SETUP AND PROCEDURE}

Behaviour of concrete under short-time erosion tests has been performed. Concrete testing specimens were cut off the $800 / 500 / 80 \mathrm{~mm}$ concrete shaft unit (nominal size DN 800, internal height $500 \mathrm{~mm}$, thickness of the wall $80 \mathrm{~mm}$ ) by the abrasive water jet to facilitate the manipulation and consequent measurements. Concrete shaft unit was produced by the vibro-compacting and pressing process. Properties of concrete shaft unit are presented in Tab. 1. Crushing load was measured according to EN 1917 Concrete manholes and inspection chambers, unreinforced, steel fibre and reinforced. 


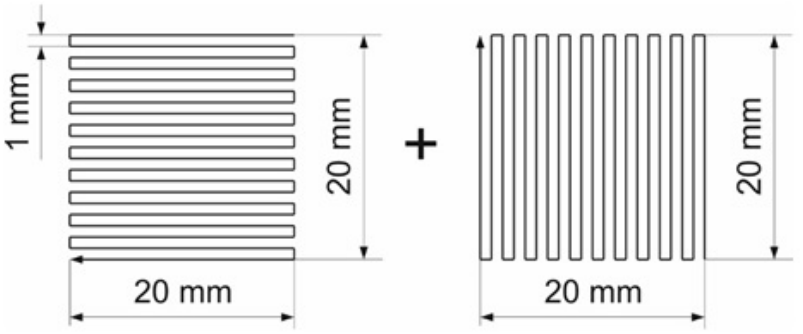

Figure 1. Combination of trajectories used for one erosion cycle during treatment of concrete specimens by the water flow.

Water absorption was measured according to EN 1917 Concrete manholes and inspection chambers, unreinforced, steel fibre and reinforced, part D. Concrete strength was measured according to ISO 4012 Concrete - determination of compressive strength of test specimens. Concrete density was measured on cubes according to EN 12390-7 Testing hardened concrete Part 7: Density of hardened concrete.

The concrete specimens were gradually eroded by either the abrasive water flow or the pure water flow acting perpendicular to the impact surface. The nozzle generating the flow moved above the specimen in trajectories shown in Fig 1 in order to affect a larger area of concrete since the abrasive water flow used had a diameter of only $1 \mathrm{~mm}$. One milling cycle was composed of two zig-zag trajectories with a crossing of $90^{\circ}$.

The concrete specimens produced were exposed to the water flow at the standoff distance of $50 \mathrm{~mm}$ (i.e. the distance between the exit of the focusing tube and the specimen). A standard cutting head Slice I with the water nozzle diameter of $0.33 \mathrm{~mm}$, focusing tube diameter of $1.02 \mathrm{~mm}$ and focusing tube length of $76.2 \mathrm{~mm}$ was used in erosion tests. Based on previous tests, the operation pressures of 40 and $80 \mathrm{MPa}$ were selected. Impact angle of the water flow used in this study was $90^{\circ}$. Traverse velocity of the flow above surface was set at $500 \mathrm{~mm} \cdot \mathrm{min}^{-1}$. Thus, one erosion cycle lasted about 110 seconds.

The Australian garnet GMA of grain size of 80 and $200 \mathrm{MESH}$ (i.e., average grain size of $177 \mu \mathrm{m}$ and $74 \mu \mathrm{m}$ according to [19]) was used for the erosion tests (see Fig. 2). For all combinations of operation pressure and abrasive grain size, three abrasive mass flow rates were tested: 10,20 and $30 \mathrm{~g} \cdot \mathrm{min}^{-1}$.

\section{Evaluation of erosion}

Eroded volume $V_{e}$ was the basic parameter used for the evaluation of erosion processes. This parameter was determined by mobile digital microscope Keyence VHX 5000. Once the eroded concrete volume of individual pockets $V_{e}$ was measured, the volumetric erosion rate $V_{r}$ was specified as follows [20]:

$$
V_{r}=\frac{V_{e}}{t_{e}},
$$

where $t_{e}$ is the exposure time

$$
t_{e}=N \cdot t_{c}
$$

$N$ is the number of erosion cycles and $t_{c}$ is the time for one erosion cycle. The volumetric erosion rate $V_{r}$ indicates the rate of erosion of surface layers of the testing samples and better determinates the erosion abilities of the flowing water or flowing water with abrasives particles.

\section{Results AND Discussion}

The results have clearly demonstrated sufficient erosive capabilities of the abrasive water flow applied on the cement-based composites. Obviously, with the increasing water pressure upstream the water nozzle and thus higher suspension speed (according to (1) to (3)), also the material removal of surface layers of the test specimens is higher (Figs. 3 and 4 . For similar findings, see, for example 9 .

At the speeds of the suspension generated at the pressure of $40 \mathrm{MPa}$, especially the hardened cement paste is removed, except of the coarse aggregate that remains uncovered after the application of the flow. At the pressure of $80 \mathrm{MPa}$, the erosion process is more aggressive and in addition to the removal of smaller structural elements of the concrete (hardened cement paste and small aggregates), softer aggregate grains in the mixture (here, for example greywacke) are cut-off or disintegrated, see Fig. 5 . However, harder aggregate (for example quartz) resists the flow even at higher speeds (Figs. 5 and 6).

The increase of the abrasive concentration causes similar phenomena as the increase of the abrasive speed [10. In addition, at higher speeds, the abrasive material has higher energy to disintegrate and erode the concrete. This fact is documented in Figs. 3 and 4 and is also obvious in the computer reconstruction of the real eroded area (Figs. 5 and 6).

The change in abrasive grain size has a similar effect on the erosion process as the change in abrasive concentration. With increasing grain size, the abrasive has greater erosion ability and thus the erosion rate increases (compare Figs. 3 and 4). Higher grain size (in our experiment $80 \mathrm{MESH}$ ) already causes cutting of hard and durable aggregate, especially at high abrasive concentrations in the flow and higher flow impact speeds.

Erosive capabilities of the pure water flow are considerably lower compared to the hydro-abrasive flow (Figs. 3 and 4), as documented e.g. in [21] or [16]. Particles of the surface layer are removed by the water flow at the point of impact to the material. The particles are consequently carried by the flow along the eroded area. This phenomena resembles the erosion of real concrete structures, whereby the released grains of the substrate flowing on the surface cause the abrasive surface erosion. When the erosion cycles are repeated, cement stone and smaller aggregate are 


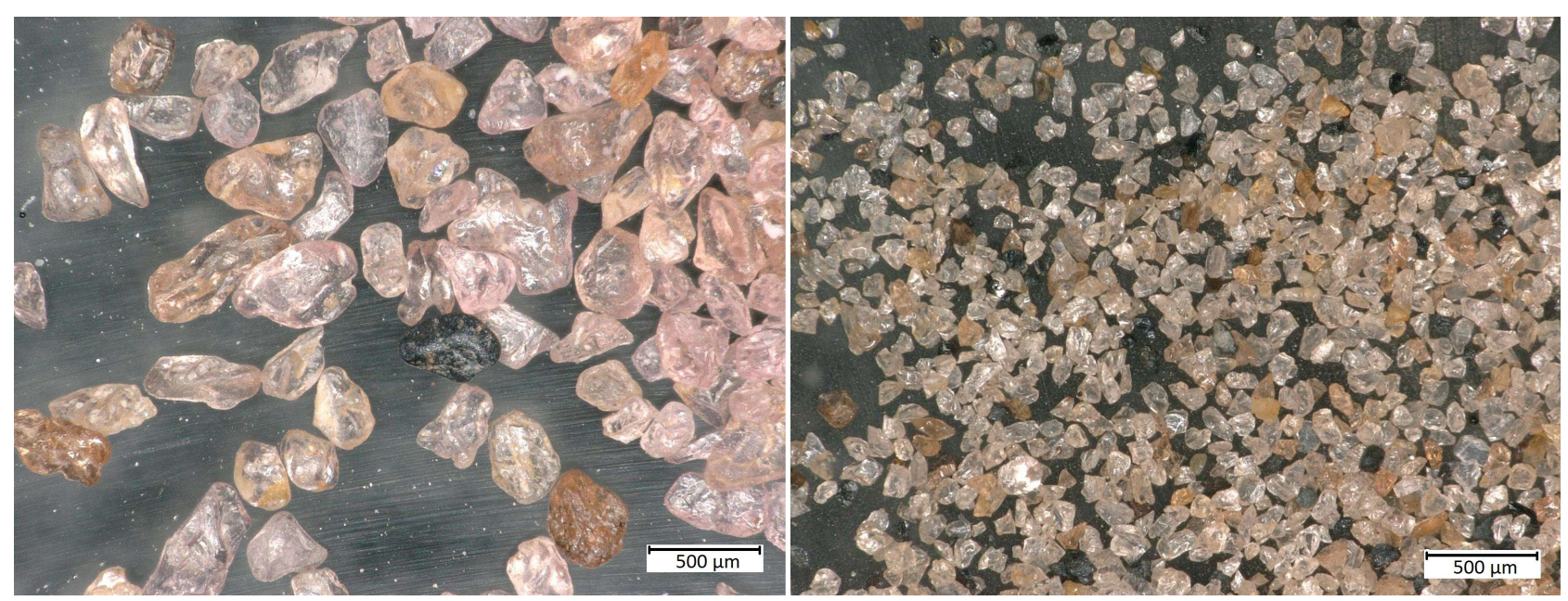

Figure 2. Grains of Australian garnet 80 MESH (left) and Australian garnet 200 MESH (right) used in experiments as an abrasive.

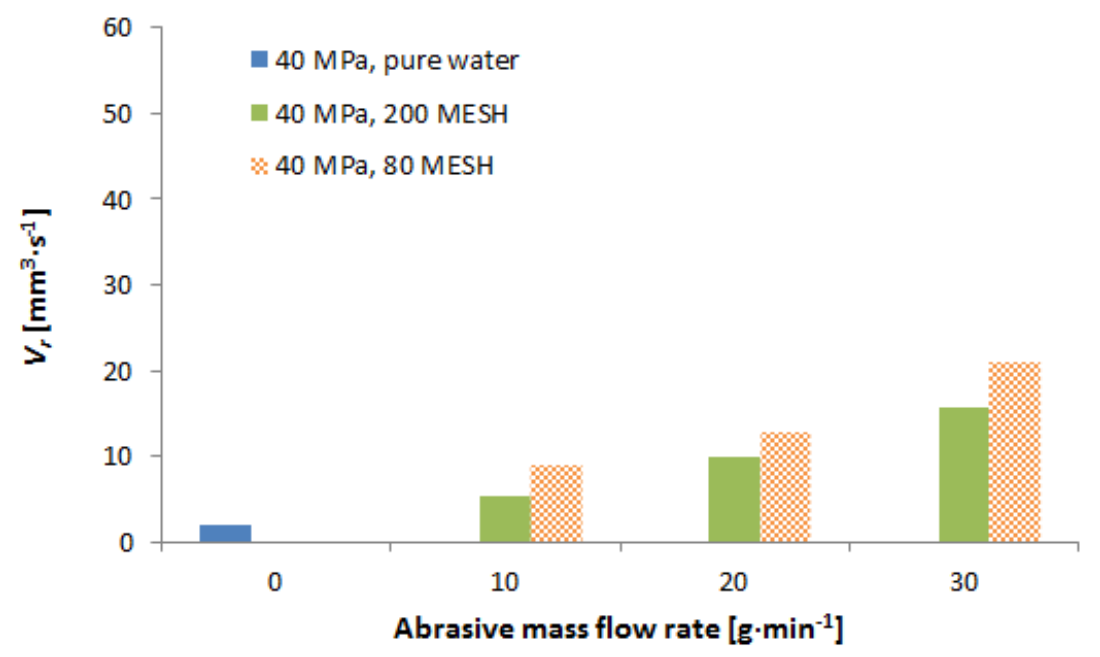

FiguRE 3. Results of the erosion tests performed in the concrete samples (water pressure of $40 \mathrm{MPa}$ ).

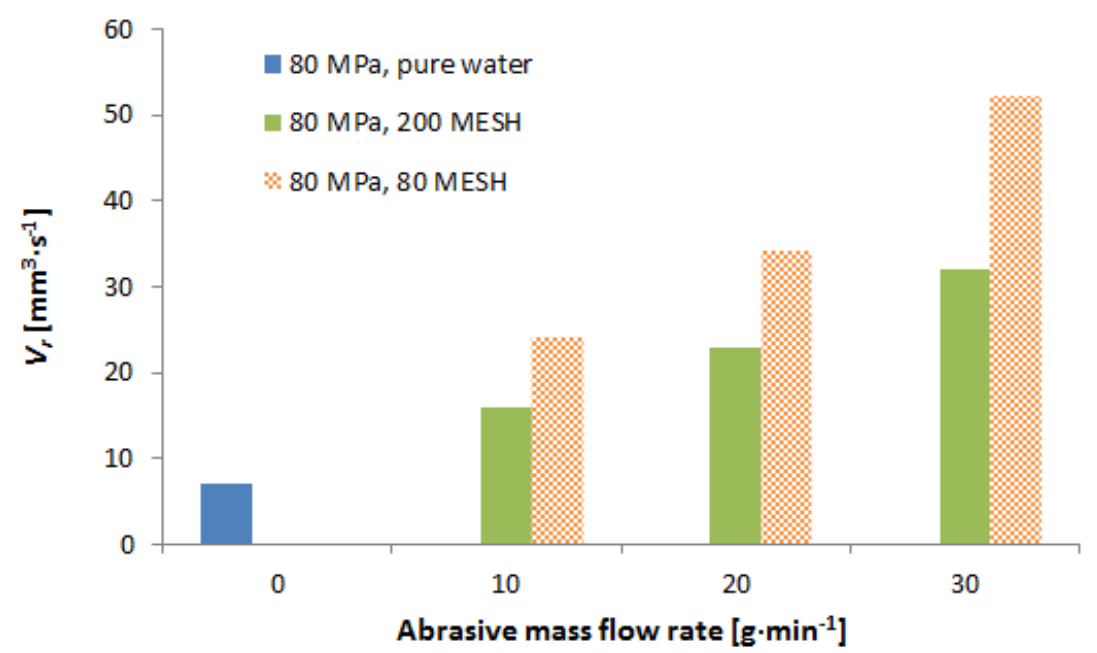

FiguRE 4. Results of the erosion tests performed in the concrete samples (water pressure of $80 \mathrm{MPa}$ ). 


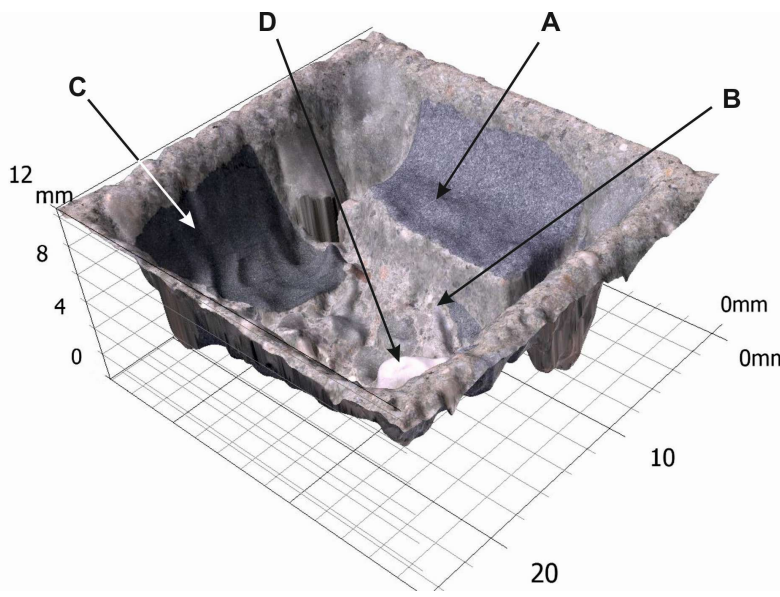

FiguRE 5. Eroded layers of concrete sample (water pressure of $80 \mathrm{MPa}$, abrasive mass flow rate of $20 \mathrm{~g} \cdot \mathrm{min}^{-1}$, Australian garnet $\left.200 \mathrm{MESH}\right)$. The amputated part of the aggregate $(\mathrm{A})$, which prevents deeper erosion. The erosion (hardened cement paste and fine aggregates) is much deeper in case of the absence of greater aggregates (B). Tangential scratches caused by the abrasives particles are well visible on the surface of some aggregates (C). Almost intact quartz aggregate (D)

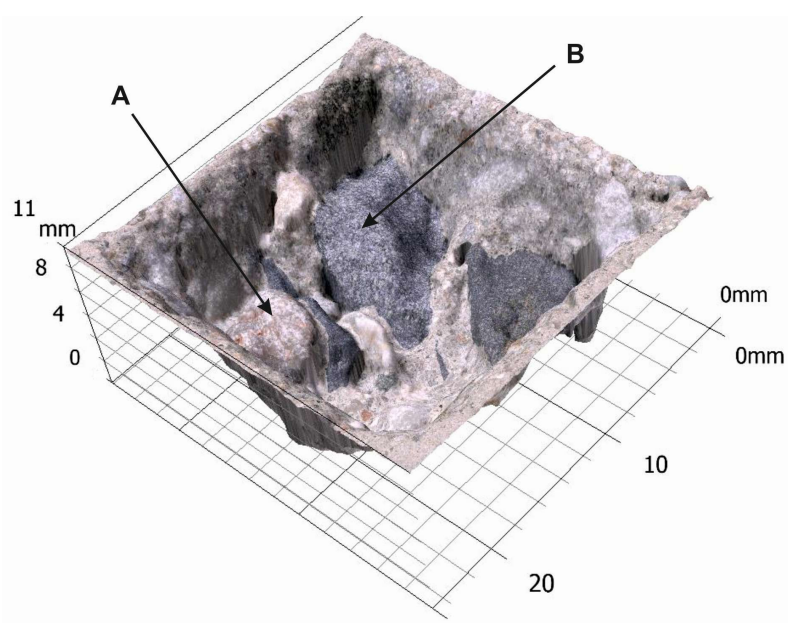

Figure 6. Eroded layers of concrete sample (water pressure of $80 \mathrm{MPa}$, abrasive mass flow rate of $20 \mathrm{~g} \cdot \mathrm{min}^{-1}$, Australian garnet $\left.80 \mathrm{MESH}\right)$. The removal of hardened cement paste and small aggregate occurs at a lower concentration of abrasives particles. Large quartz grain (A) are uncovered but intact. Due to the lack of erosive energy of the abrasives particles in the flow, also the softer aggregate remain intact, for instance greywacke (B). gradually washed out and large aggregates become uncovered. If the power of the water flowing along the surface exceeds the adhesive forces between the uncovered aggregate and the substrate, the aggregate is split-off from the matrix (Fig. 7) and the abrasive erosion process is repeated.

Regarding the number of erosion cycles applied at the same area of the concrete specimen, it is evident that multiple cycles cause greater erosion of the material. However, the amount of the material removed decreases in every subsequent cycle (e.g., Fig. 8 for water flow without abrasives). This is mainly due to the presence of large aggregate at greater depths from the original surface and also due to greater distances of the newly created surface from the nozzle orifice and thus smaller impact energy per unit area. At the same time, the ratio of the abrasive erosion rate between faster and slower water flows increases with every subsequent cycle (Fig. 8).

The comparison of surfaces of identical aggregate exposed to pure water (left) and abrasive water flow (right) is visible on the Fig. 9. Pure water stream removes the cement stone to the surface of the aggregate only, contrariwise the abrasive stream removes and disintegrates the aggregate. There is a visible change in the surface of the aggregate.

\section{Conclusions}

From the experimental research in the field of the pure and abrasive water flow moving and acting perpendicular to the concrete surface, it follows that:

(1.) Application of high-speed water flows is a suitable quick method for simulating the erosion wear of concrete exposed to the effects of flowing liquids.

(2.) In order to achieve similar effect to real concrete construction erosion, the pure high-speed water flow or hydro-abrasive flow with low impact speeds of the abrasive material, low abrasive concentration in the water flow and small grain sizes should be used.

(3.) The erosion rate increases with the increase in the flow speed, abrasive content and abrasive grain size. However, at high erosion rates, the concrete surface is no longer eroded and structural elements of the concrete are cut off, which does not correspond to the real erosion caused by flowing liquids.

(4.) In order to increase the erosion wear, multiple erosion cycles can be applied on the same surface. At first, the hardened cement paste and small aggregates are removed by the high-speed water flow (pure or abrasive) from the disintegrated concrete surface. Large aggregate thus becomes uncovered and it is removed in subsequent erosion cycles.

\section{ACKNOWLEDGEMENTS}

This work was supported by grant of the Czech Science Foundation (18-25035S) and by project of the Institute of Clean Technologies for Mining and the Utilization of Raw 


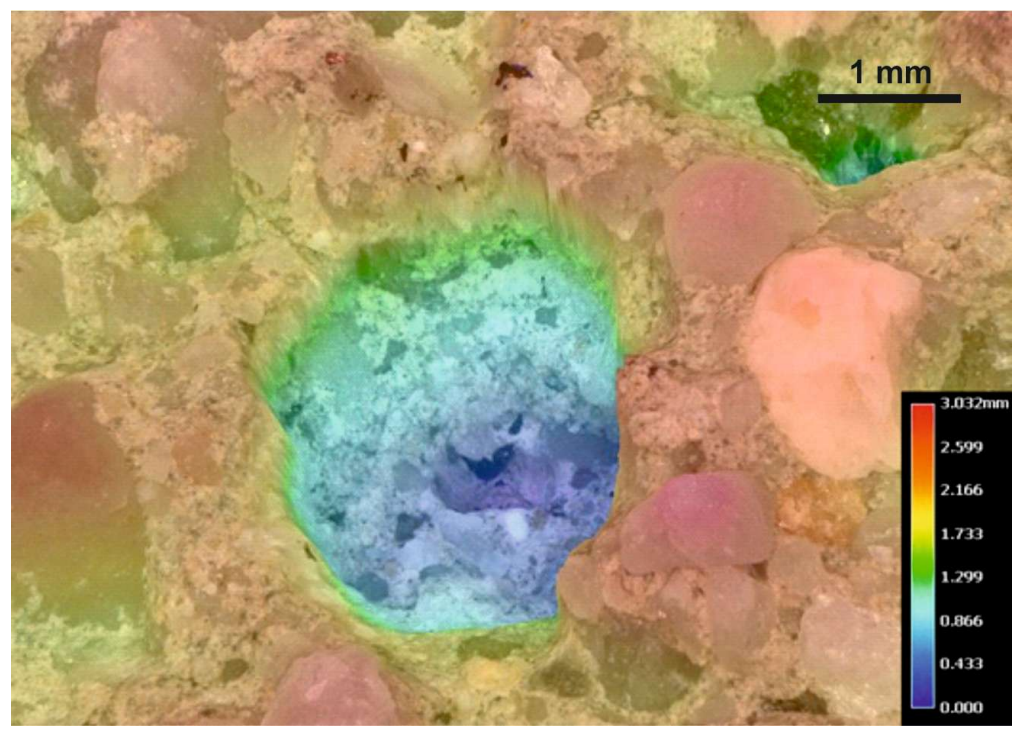

FigURE 7. Split-off stone after erosion test by pure water flow (water pressure of $80 \mathrm{MPa}$ ).

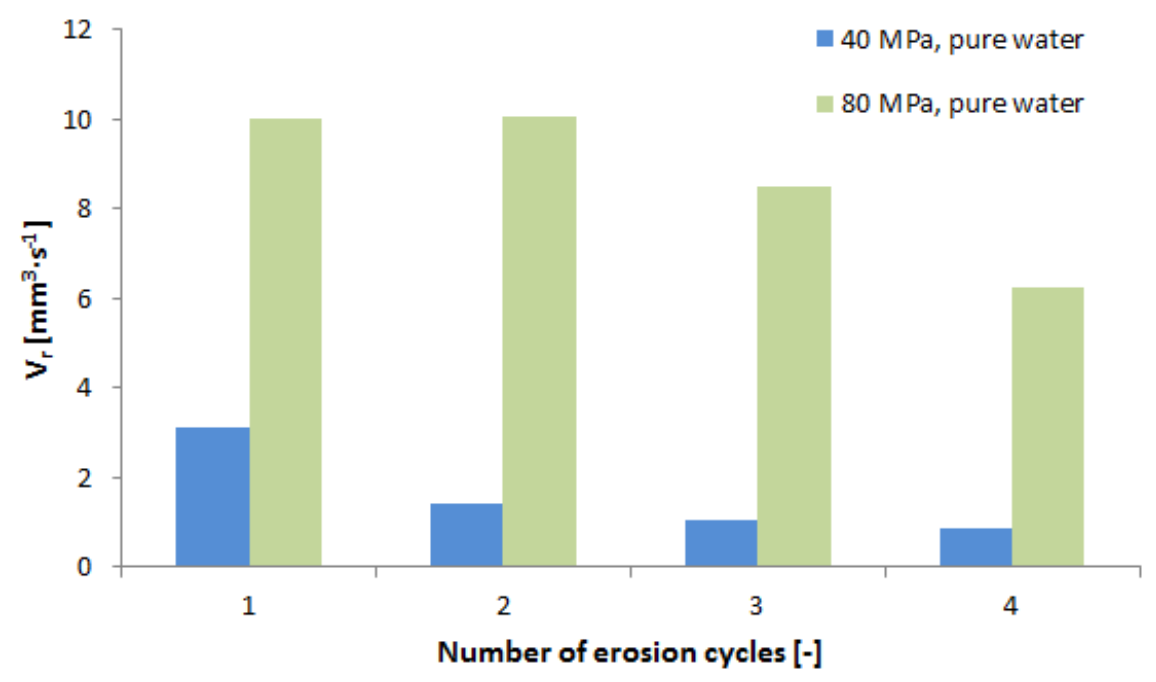

FiguRE 8. Influence of number of erosion cycles on volumetric removal rate.
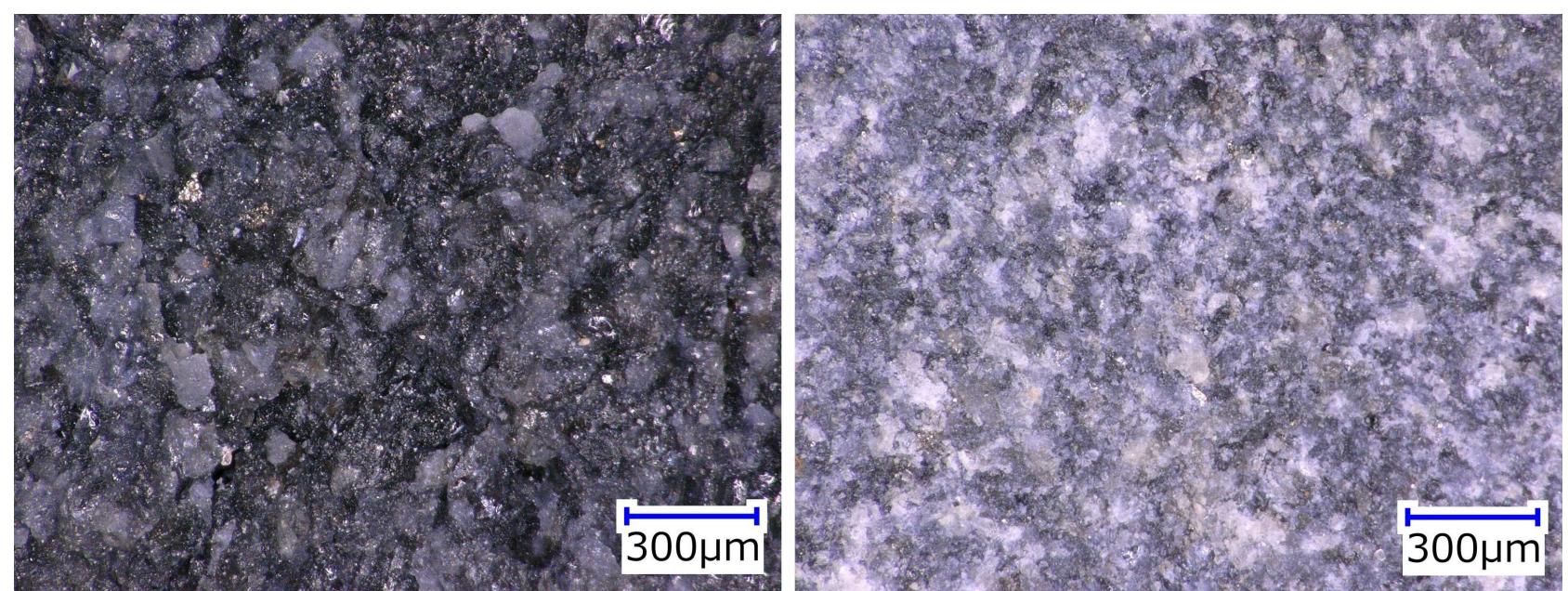

FiguRE 9. Left - surface of aggregate exposed to pure water flow; right - surface of aggregate eroded by abrasive particles contained in hydro-abrasive suspension flow. Changes in colour of the surface are well visible. 
Materials for Energy Use - Sustainability program, reg. no. LO1406 financed by the Ministry of Education, Youth and Sports of the Czech Republic. The authors are very thankful for the support.

\section{REFERENCES}

[1] ACI 210R-93 - Erosion of concrete in hydraulic structures. Standard, American Concrete Institute, 1998.

[2] J. C. A. Galvão, K. F. Portella, A. C. M. Kormann. Abrasive effects observed in concrete hydraulic surfaces of dams and application of repair materials. In M. Adamiak (ed.), Abrasion Resistance of Materials, chap. 2. IntechOpen, Rijeka, 2012. DOI:10.5772/27964

[3] E. Horszczaruk. Abrasion resistance of high-strength concrete in hydraulic structures. Wear 259:62-69, 2005. DOI:10.1016/j.wear.2005.02.079

[4] ASTM C 1138-97 - Standard test method for abrasion resistance of concrete (underwater method). Standard, American Society for Testing and Materials, West Conshohocken, 2002.

[5] E. Horszczaruk. Hydro-abrasive erosion of high performance fiber-reinforced concrete. Wear 267:110-115, 2009. DOI:10.1016/j.wear.2008.11.010.

[6] E. Horszczaruk. Abrasion resistance of high strength fibre-reinforced concrete. In 6th RILEM Symposium on Fibre-Reinforced Concretes - BEFIB 2004. Varenna, Italy, 2004.

[7] H. Binici, O. Aksogan, E. Bahsude Gorur, et al. Hydro-abrasive erosion of concrete incorporating ground blast-furnace slag and ground basaltic pumice. Construction and Building Materials 23:804-811, 2009. DOI:10.1016/j.conbuildmat.2008.03.003

[8] A. Momber, R. Kovacevic. Accelerated high speed water erosion test for concrete wear debris analysis. Tribology Transactions 39:943-949, 1996. DOI:10.1080/10402009608983616

[9] X. G. Hu, A. W. Momber, Y. G. Yin. Hydro-abrasive erosion of steel-fibre reinforced hydraulic concrete. Wear 253(7):848-854, 2002. DOI:10.1016/S0043-1648(02)00215-6

[10] X. G. Hu, A. W. Momber, Y. Yin. Erosive wear of hydraulic concrete with low steel fiber content. Journal of Hydraulic Engineering 132(12):1331-1340, 2006. DOI:10.1061/(ASCE)0733-9429(2006)132:12(1331)
[11] A. Momber, R. Mohan, R. Kovacevic. On-line analysis of hydro-abrasive erosion of pre-cracked materials by acoustic emission. Theoretical and Applied Fracture Mechanics 31:1-17, 1999. DOI:10.1016/S0167-8442(98)00062-7

[12] A. Momber. Short-time cavitation erosion of concrete. Wear 241:47-52, 2000. DOI:10.1016/S0043-1648(00)00348-3

[13] A. Momber. Effects of erodent flow energy and local exposure time on the erosion of cement-based composites due to high-speed hydro-abrasive flow. Wear 378-379:145-154, 2017. DOI:10.1016/j.wear.2017.01.120

[14] A. W. Momber. Stress-strain relation for water-driven particle erosion of quasi-brittle materials. Theoretical and Applied Fracture Mechanics 35(1):19-37, 2001. DOI:10.1016/S0167-8442(00)00046-X

[15] A. Momber. A probabilistic model for the erosion of cement-based composites due to very high-speed hydro-abrasive flow. Wear 368-369:39-44, 2016. DOI:10.1016/j.wear.2016.08.011

[16] A. Momber. Principles of Abrasive Water Jet Machining. Elsevier, London, 1998.

[17] M. Zeleňák, J. Foldyna, P. Martinec, et al. Measurement and analysis of abrasive particles velocities in AWJ. In Water Jet 2015. Proceedings of the Int. Conf., pp. 221-232. Ostrava, 2015.

[18] M. Zelenak, J. Scucka, K. Soucek. Velocity measurements on continuous micro water jet using fluorescent PMMA seeding particles. In Water Jet 2017. Proceedings of the Int. Conf. Ostrava, 2017.

[19] P. Martinec, J. Foldyna, L. Sitek, et al. Abrasives for AWJ cutting. In INCO - COPERNICUS No. IC 15-CT98-0821. Institute of Geonics, 2002.

[20] P. Hlaváček, L. Sitek, R. Hela, L. Bodnárová. Erosion Test with High-speed Water Jet Applied on Surface of Concrete Treated with Solution of Modified Lithium Silicates, pp. 135-143. Springer, Basel, Switzerland, 2019. DOI:10.1007/978-3-319-99353-9_15

[21] D. A. Summers. Waterjetting technology. E \& FN Spon, London, 1995. 